\title{
Physical activity in confined conditions as an indicator of free-living physical activity
}

Citation for published version (APA):

Westerterp, K. R., \& Kester, A. D. M. (2003). Physical activity in confined conditions as an indicator of free-living physical activity. Obesity Research, 11(7), 865-68. https://doi.org/10.1038/oby.2003.119

Document status and date:

Published: 01/01/2003

DOI:

10.1038/oby.2003.119

Document Version:

Publisher's PDF, also known as Version of record

Document license:

Taverne

Please check the document version of this publication:

- A submitted manuscript is the version of the article upon submission and before peer-review. There can be important differences between the submitted version and the official published version of record.

People interested in the research are advised to contact the author for the final version of the publication, or visit the DOI to the publisher's website.

- The final author version and the galley proof are versions of the publication after peer review.

- The final published version features the final layout of the paper including the volume, issue and page numbers.

Link to publication

\footnotetext{
General rights rights.

- You may freely distribute the URL identifying the publication in the public portal. please follow below link for the End User Agreement:

www.umlib.nl/taverne-license

Take down policy

If you believe that this document breaches copyright please contact us at:

repository@maastrichtuniversity.nl

providing details and we will investigate your claim.
}

Copyright and moral rights for the publications made accessible in the public portal are retained by the authors and/or other copyright owners and it is a condition of accessing publications that users recognise and abide by the legal requirements associated with these

- Users may download and print one copy of any publication from the public portal for the purpose of private study or research.

- You may not further distribute the material or use it for any profit-making activity or commercial gain

If the publication is distributed under the terms of Article $25 \mathrm{fa}$ of the Dutch Copyright Act, indicated by the "Taverne" license above, 


\title{
Physical Activity in Confined Conditions as an Indicator of Free-Living Physical Activity
}

\author{
Klaas R. Westerterp* and Arnold D.M. Kester ${ }^{\dagger}$
}

\begin{abstract}
WESTERTERP, KLAAS R. AND ARNOLD D.M. KESTER. Physical activity in confined conditions as an indicator of free-living physical activity. Obes Res. 2003; 11:865-868.

Objective: The main determinants of daily energy expenditure are body size and physical activity. Activity energy expenditure is the most variable component of total energy expenditure. It was assessed whether the physical activity level in confined conditions is an indicator of free-living physical activity.

Research Methods and Procedures: Activity energy expenditure was measured over 1 day in a confined environment of a respiration chamber (floor space, $7.0 \mathrm{~m}^{2}$ ), where activities were restricted to low-intensity activities of daily living, and over 2 weeks in a free-living environment using doubly labeled water. Subjects were 16 women and 29 men (age, $31 \pm 10$ years; BMI, $24.2 \pm 2.7 \mathrm{~kg} / \mathrm{m}^{2}$ ).
\end{abstract}

Results: The free-living activity level of the subjects, as a multiple of resting energy expenditure, was $1.76 \pm 0.13$. Activity energy expenditure in the chamber was $47 \pm 13 \%$ of the value in daily life, and the two values were correlated ( $r=0.50, p<0.001$; partial correlation corrected for age, gender, and BMI: 0.40, $p<0.01)$. The chamber value explained $25 \%$ of the total variance in free-living activity energy expenditure.

Discussion: The activity level of a subject under sedentary conditions is an indicator of activity energy expenditure in daily life, showing the importance of nonexercise activity for daily energy expenditure.

Key words: indirect calorimetry, respiration chamber, doubly labeled water, body size, exercise

Received for review January 27, 2003

Accepted in final form May 5, 2003.

*Department of Human Biology and $†$ Department of Methodology and Statistics, Maastricht University, Maastricht, The Netherlands.

Address correspondence to Klaas R. Westerterp, Department of Human Biology, Maastricht University, PO Box 616, 6200 MD Maastricht, The Netherlands.

E-mail: K.Westerterp@HB.Unimaas.NL

Copyright () 2003 NAASO

\section{Introduction}

Daily energy expenditure can be divided into three components: basal metabolic rate (BMR), ${ }^{1}$ diet-induced energy expenditure, and activity-induced energy expenditure (AEE). BMR represents the energetic costs of the processes essential for life. Diet-induced energy expenditure results from the digestion, absorption, and conversion of the monomeric forms of the absorbed macronutrients to their polymeric form. AEE is the energy expenditure associated with muscular contractions to perform body postures and movements, including exercise. Under most circumstances, individual BMR accounts for the largest proportion of daily energy expenditure or average daily metabolic rate (ADMR) and is mainly determined by body size. Dietinduced energy expenditure is $\sim 10 \%$ of ADMR in subjects consuming an average mixed diet that meets energy requirements (1). AEE is the most variable component of ADMR. In the general population, physical activity level (PAL; ADMR/BMR) ranges between 1.2 and 2.5 (2). As a fraction of ADMR, AEE varies from $5 \%$ in a subject with a minimum PAL of 1.2 to $50 \%$ in a subject with a PAL of 2.5. At a PAL value of 1.75 , the average reported for the general population $(3,4)$, AEE is one-third of ADMR.

Recently, Snitker et al. (5) showed, for a group of healthy Pima Indians, that AEE, as measured in a respiration chamber, was correlated to habitual, free-living physical activity. They speculated from these data that there might be a genetic determinant of AEE and encouraged further studies. AEE has been shown to be important for the maintenance of body weight (6). An increase in daily PALs could decrease the rising prevalence of obesity (7). Here, to quantify the importance of nonexercise activity for daily energy expenditure, we assessed whether the activity level of a subject under sedentary conditions is an indicator for AEE in daily life.

\footnotetext{
${ }^{1}$ Nonstandard abbreviations: BMR, basal metabolic rate; AEE, activity-induced energy expenditure; ADMR, average daily metabolic rate; PAL, physical activity level; 24EE, 24-hour energy expenditure; $\mathrm{SMR}$, sleeping metabolic rate; $\mathrm{AEE}_{\mathrm{ch}}$, activity-induced energy expenditure in the chamber; $\mathrm{AEE}_{\mathrm{fl}}$, activity-induced energy expenditure in free-living activity.
} 


\section{Research Methods and Procedures}

Subjects were 16 women and 29 men, with an average age of $31 \pm 10$ years (range, 19 to 61 years) and a BMI of $24.2 \pm 2.7 \mathrm{~kg} / \mathrm{m}^{2}$ (range, 19.4 to $30.4 \mathrm{~kg} / \mathrm{m}^{2}$ ). They were participants in studies on effects of intake pattern and diet composition on energy expenditure $(8,9)$. Selection criteria included being white, living within $30 \mathrm{~km}$ from Maastricht, participating in sporting activities $<7 \mathrm{~h} / \mathrm{wk}$, having an alcohol consumption of $<21 \mathrm{drinks} /$ wk for women and $<28$ drinks/wk for men, and having no dietary restrictions. All subjects were certified by a staff physician to be in good health and gave informed consent to participate in the study after procedures were explained to them. The protocol was approved by the university ethics committee.

Subjects were weight stable at least 6 months before and during the study. Observations included measurement of energy expenditure over $24 \mathrm{~h}$ (24EE) in a respiration chamber and under daily living conditions (ADMR) over a 2-week interval using doubly labeled water.

Measurement of energy expenditure in the respiration chamber was performed as described before (10). The chamber measured $3.10 \times 2.25 \mathrm{~m}$ and was furnished with a bed, chair, table, TV, radio, telephone, wash bowl, and toilet facilities. During daytime hours, subjects were allowed to move freely, sit, lie down, study, use the telephone, listen to the radio, and watch television; only sleeping and purposeful exercise were not allowed. At night, subjects were supposed to sleep from 11:00 PM until 7:00 AM, when lights were switched off. Body movement was monitored by means of a radar system based on the Doppler principle. Subjects were fed according to estimated energy balance. Sleeping metabolic rate (SMR) was measured from 3:00 AM to 6:00 AM, when subjects were asleep.

ADMR was measured over a 2-week period, immediately after the measurement of 24EE. Dose, sampling protocol, sample analysis, and calculation procedure were as described before $(11,12)$. Briefly, subjects were given a weighed dose of water with a measured enrichment of $\sim 5$ atoms $\%{ }^{2} \mathrm{H}$ and 10 atoms $\%{ }^{18} \mathrm{O}$, so that baseline levels were increased with $150 \mathrm{ppm}$ for ${ }^{2} \mathrm{H}$ and $300 \mathrm{ppm}$ for ${ }^{18} \mathrm{O}$. Urine samples for isotope measurement were collected before dosing at night, from the second and last voiding on the next day, and after 7 and 14 days. Isotope abundance in the urine samples was measured with an isotope-ratio mass spectrometer (Aqua Sira; VG Isogas, Cheshire, United Kingdom). $\mathrm{CO}_{2}$ production was calculated from isotope elimination rates, as calculated from the slope of the elimination curve, correcting for changes in body water assumed to be proportional to changes in body mass from the start to the end of the observation interval. $\mathrm{CO}_{2}$ production was converted to ADMR using an energy equivalent based on the individual macronutrient composition of the diet.

$\mathrm{AEE}$ in the chamber $\left(\mathrm{AEE}_{\mathrm{ch}}\right)$ and under free-living conditions $\left(\mathrm{AEE}_{\mathrm{fl}}\right)$ were calculated, respectively, with the equa-

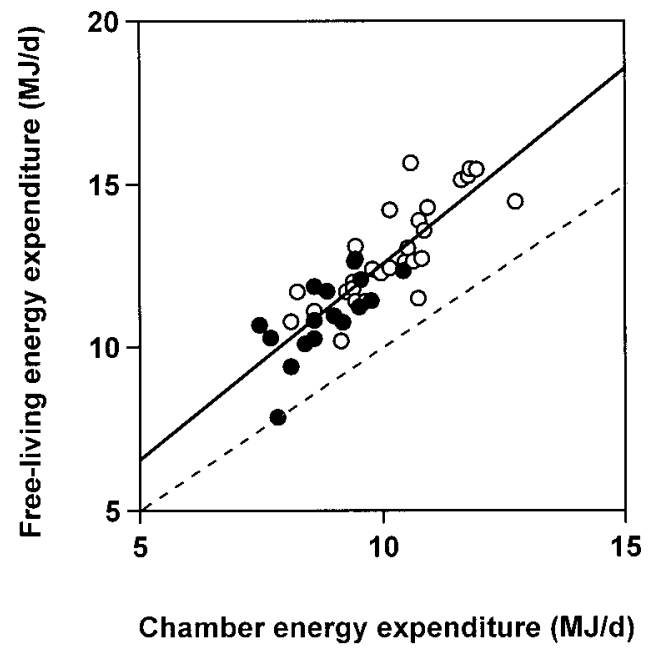

Figure 1: Free-living energy expenditure plotted as a function of energy expenditure in the confined environment of a respiration chamber (women, closed circles; men, open circles), with the line of identity (dotted) and the linear regression line (continuous, $r=$ $0.85, p<0.0001)$.

tions: $\mathrm{AEE}_{\mathrm{ch}}=24 \mathrm{EE}-(0.1 \times 24 \mathrm{EE}+\mathrm{SMR})$ and $\mathrm{AEE}_{\mathrm{fl}}$ $=\mathrm{ADMR}-(0.1 \times \mathrm{ADMR}+\mathrm{SMR})$, where diet-induced energy expenditure was estimated as $10 \%$ of ADMR (1). AEE was normalized by division by body weight, an appropriate means for comparing the volume (intensity $\times$ time) of physical activity among individuals of different body sizes (13). In a subgroup of 30 subjects, body movement in free-living conditions was evaluated during a 7-day period with a tri-axial accelerometer (14). Partial correlations of chamber and free-living energy expenditure parameters were calculated with correction for age, gender, and BMI.

\section{Results}

Free-living energy expenditure was higher than energy expenditure in the confined environment of a respiration chamber for all subjects, and the two values were closely correlated (Figure 1, $r=0.85, p<0.0001$; partial correlation, $0.65 ; p<0.0001)$. The activity level of the subjects in the respiration chamber $(24 \mathrm{EE} / \mathrm{SMR})$ was $1.40 \pm 0.06$ (range, 1.30 to 1.58 ). The activity level in free-living conditions (ADMR/SMR) was $1.76 \pm 0.14$ (range, 1.38 to 2.04). The partial correlation of chamber and free-living ADMR/SMR was $0.38(p<0.05)$. AEE in the chamber was $47 \pm 13 \%$ of the value in daily life, and the two values were correlated (Figure 2, $r=0.50, p<0.001$; partial correlation, $0.40 ; p<0.01)$. In a subgroup of 30 subjects, there was a similar relation between body movement in daily life (accelerometer counts) and in the chamber (radar counts): $r=0.57, p<0.001$. 


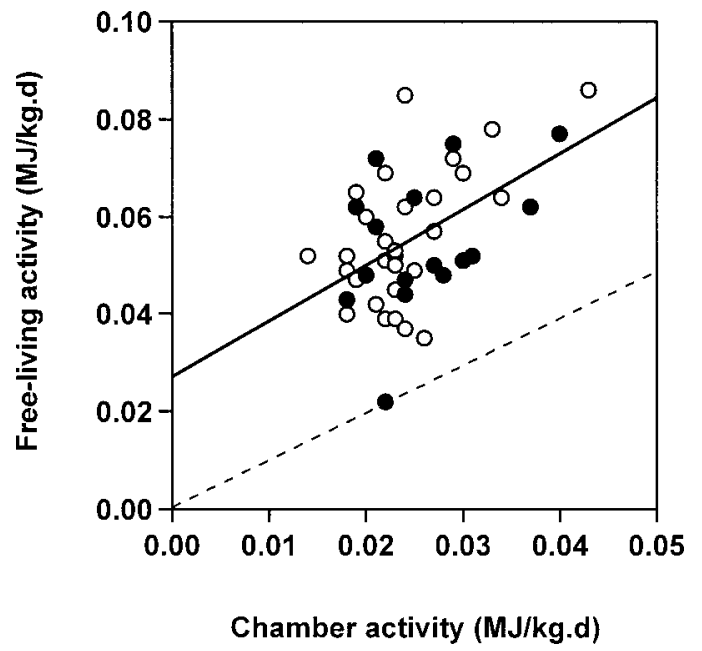

Figure 2: Free-living activity energy expenditure plotted as a function of activity energy expenditure in the confined environment of a respiration chamber (women, closed circles; men, open circles), with the line of identity (dotted) and the linear regression line (continuous, $r=0.50, p<0.001$ ).

There were no significant effects of BMI, gender, and age on AEE. Women had a lower 24EE and a lower ADMR (Figure 1). However, AEE adjusted for differences in body weight was similar for women and men in the chamber $(0.026 \pm 0.006$ and $0.024 \pm 0.006 \mathrm{MJ} / \mathrm{kg}$, respectively), as well as free living $(0.055 \pm 0.014$ and $0.056 \pm 0.014$ $\mathrm{MJ} / \mathrm{kg}$, respectively).

\section{Discussion}

The activity level of the subjects in free-living conditions was close to the average reported for the general population (2-4). The activity level of the subjects in the respiration chamber was very close to literature values. Snitker et al. (5) observed a value of $1.42 \pm 0.10$ in a slightly larger chamber (3.33 m long and $2.45 \mathrm{~m}$ wide, floor space $8.2 \mathrm{~m}^{2}$ ) compared with the $7.0-\mathrm{m}^{2}$ chamber in the current study. Astrup et al. (15) reported a value of 1.27 for a slightly smaller chamber ( $3.66 \mathrm{~m}$ long and $1.77 \mathrm{~m}$ wide, floor space $\left.6.5 \mathrm{~m}^{2}\right)$. All chamber values mentioned above are for conditions where subjects were allowed to move around without access to exercise equipment like a treadmill, ergometer, or stepping benches.

Physical activity in confined conditions was measured in a single 24-h stay in a room calorimeter. It has frequently been shown that 24EE, as measured in a respiration chamber, is reproducible (15-18). Therefore, this 24EE can be used to estimate physical activity in confined conditions.

One could speculate from these results that a major part of AEE in free-living conditions is associated with low- -intensity activities such as lying, sitting, and standing, and moderate intensity activities such as walking. We recently showed that subjects with a PAL ranging from 1.51 to 2.04, a subgroup of the subjects of the current study, spent on average $9 \%$ of the active time in high-intensity activity (19). The data clearly showed that in the normal PAL range, the distribution of time spent at activities with low and moderate intensity is the major contributor to the daily activity level. High-intensity activity does not have much impact as a determinant of PAL in the normal population. An average subject with a PAL of 1.75 spends, respectively, 65\%, 25\%, and $9 \%$ of the active time in low-, moderate-, and highintensity activity. When the ratio of the energy costs for low, moderate, and high intensity is 1:2:4, high-intensity activity contributes $\sim 25 \%$ to AEE.

We adjusted AEE for differences in body weight by division by body weight as a means for comparing the volume (intensity $\times$ time) of physical activity among individuals of different body size. Ekelund et al. (20) compared AEE as well as activities in obese (BMI $>30 \mathrm{~kg} / \mathrm{m}^{2}$ ) and matched nonobese adolescents. AEE was measured with doubly labeled water, and activities were measured simultaneously with accelerometry. The obese performed fewer activities than the nonobese despite no difference in PAL. Activity counts in the obese, as monitored with an accelerometer, were $68 \%$ of the nonobese, and AEE in megajoules per kilogram was similarly lower at $65 \%$ of the values in the nonobese.

Future studies should indicate whether there is a genetic component in $\mathrm{AE}$, as suggested by a $>2$-fold variation in AEE among individuals in the same confined environment of a respiration chamber and the significant relation with AEE in free-living conditions. Pérusse et al. (21) have shown that the level of habitual physical activity, as derived from a 3-day activity record, has a genetic component. Additionally, behavioral choices could be similar within subjects and different among subjects whether or not they are in a confined living space.

\section{Acknowledgments}

There was no outside funding/support for this study.

\section{References}

1. Schutz Y, Bessard T, Jéquier E. Diet-induced thermogenesis measured over a whole day in obese and nonobese women. Am J Clin Nutr. 1984;40 542-52.

2. Westerterp KR. Alterations in energy balance with exercise. Am J Clin Nutr. 1998;68:970S-4S.

3. Black AE, Coward WA, Cole TJ, Prentice AM. Human energy expenditure in affluent societies: an analysis of 574 doubly-labelled water measurements. Eur J Clin Nutr. 1996; 50:72-92. 
4. Westerterp KR. Obesity and physical activity. Int J Obes Relat Metab Disord. 1999;23(suppl 1):59-64.

5. Snitker S, Tataranni, Ravussin E. Spontaneous physical activity in a respiratory chamber is correlated to habitual physical activity. Int J Obes Relat Metab Disord. 2001;25: 1481-6.

6. Schoeller DA, Shay K, Kushner RF. How much physical activity is needed to minimize weight gain in previously obese women? Am J Clin Nutr. 1997;66:551-6.

7. Weinsier RL, Hunter GR, Desmond RA, Byrne NM, Zuckerman PA, Darnell BE. Free-living activity energy expenditure in women successful and unsuccessful at maintaining normal body weight. Am J Clin Nutr. 2002;75:499-504.

8. Verboeket-van de Venne WPHG, Westerterp KR, Kester ADM. Effect of the pattern of food intake on human energy metabolism. Br J Nutr. 1993;70:103-15.

9. Westerterp KR, Verboeket-van de Venne WPHG, Bouten CVC, De Graaf C, Van het Hof KH, Weststrate JA. Energy expenditure and physical activity in subjects consuming fullor reduced-fat diets. Br J Nutr. 1996;76:785-95.

10. Schoffelen PFM, Westerterp KR, Saris WHM, Ten Hoor F. A dual-respiration chamber system with automated calibration. J Appl Physiol. 1997;83:2064-72.

11. Westerterp KR, Wouters L, Van Marken Lichtenbelt WD. The Maastricht protocol for the measurement of body composition and energy expenditure with labeled water. Obes Res. 1995;3(suppl 1):49-57.

12. Westerterp KR. Body composition, water turnover and energy turnover assessment with labelled water. Proc Nutr Soc. 1999;58:945-51.
13. Schoeller DA, Jefford G. Determinants of the energy costs of light activities: inferences for interpreting doubly labeled water data. Int J Obes Relat Metab Disord. 2002;26:97-101.

14. Bouten CVC, Verboeket-van de Venne WPHG, Westerterp KR, Verduin M, Janssen JD. Physical activity assessment: comparison between movement registration and doubly labeled water. J Appl Physiol. 1996;81:1019-26.

15. Astrup A, Thorbeck G, Lind J, Isaksson B. Prediction of 24-h energy expenditure and its components from physical characteristics and body composition in normal-weight humans. Am J Clin Nutr. 1990;52:777-83.

16. De Boer J, Van Es AJ, Vogt JE, Van Raay, Hautvast JG. Reproducibility of $24 \mathrm{~h}$ energy expenditure measurements using a human whole body indirect calorimeter. $\mathrm{Br} J \mathrm{Nutr}$. 1987;57:201-9.

17. Rumpler WV, Seale JL, Conway JM, Moe PW. Repeatability of 24-h energy expenditure measurements in humans by indirect calorimetry. Am J Clin Nutr. 1990;51:147-52.

18. White MD, Bouchard G, Beumann B, et al. Reproducibility of 24-h energy expenditure and macronutrient oxidation rates in an indirect calorimeter. J Appl Physiol. 1996;80:133-9.

19. Westerterp KR. Pattern and intensity of physical activity. Nature. 2001;410:539.

20. Ekelund U, Aman J, Yngve A, Renman C, Westerterp K, Sjöström M. Physical activity but not energy expenditure is reduced in obese adolescents: a case-control study. Am J Clin Nutr. 2002;76:935-41.

21. Pérusse L, Tremblay A, Leblanc C, Bouchard C. Genetic and environmental influences on level of habitual physical activity and exercise participation. Am J Epidemiol. 1989;129: 1012-22. 